\title{
Mapeando o Pós-Keynesianismo: uma abordagem cientométrica
}

\author{
Bruno Roberto Dammski \\ Doutorando - Faculdade de Ecnomia, Administração e Contabilidade (USP/FEA) \\ Endereço: Av. Professor Luciano Gualberto, 908 - Cidade Universitária - São Paulo/SP \\ CEP: 05508-010 - E-mail: brunord21@gmail.com
}

\author{
Marco Antonio Ribas Cavalieri \\ Professor - Universidade Federal do Paraná (UFPR) \\ Endereço: Av. Prefeito Lothário Meissner, 632 - Curitiba/PR \\ CEP: 80210-170 - E-mail: cavaga@uol.com.br \\ José Simão de Paula Pinto \\ Professor - Universidade Federal do Paraná (UFPR) \\ Endereço: Av. Prefeito Lothário Meissner, 632 - Curitiba/PR \\ CEP: 80210-170 - E-mail: simao@ufpr.br
}

Recebido: 29/04/2016. Aceite: 29/05/2017.

\section{Resumo}

O presente artigo tem como objetivo estudar a corrente Pós-keynesiana na Ciência Econômica, visando identificar suas principais características. A metodologia empregada para isso combina conceitos filosóficos e linguísticos através do chamado finitismo de significados. Dentro dessa perspectiva, utiliza ferramentas computacionais e cientométricas, mais especificamente a chamada análise de $\mathrm{Co}$-word, para fornecer uma definição da corrente pós-keynesiana em economia. O trabalho também inclui um resgate da história do Pós-keynesianismo desde 1936 até os nossos dias.

\section{Palavras-Chave}

Pós-keynesianismo. Finitismo de significados. Análise de Co-word. História do pensamento econômico.

\begin{abstract}
This article analyses the Post Keynesian movement in economics in order to establish its defining characteristics. The methodology used to accomplish this objective is a combination of philosophic and linguistic conceptions commonly referred as meaning finitism. Given the meaning finitism conception of how to define a linguistic expression, we use a computational and scientometric technique named Co-word analysis to obtain a definition of Post Keynesian economics. Also, we present a brief account of the history of the Post Keynesian movement since its beginning in 1936 until the present time.
\end{abstract}

\section{Keywords}

Post Keynesian. Meaning finitism. Co-word analysis. History of economic thought.

\section{JEL Classification}

B29. B41. 


\section{Introdução}

Na ciência econômica, ao longo de sua história, é comum a existência de correntes teórico-metodológicas alternativas à perspectiva dominante, usualmente denominada de mainstream. Na segunda metade do século $\mathrm{XX}$, economistas pertencentes a essas correntes começaram a entender suas perspectivas como parte do que se chama, agora, de heterodoxia. Segundo Backhouse (2004), uma heterodoxia é mais do que um mero conjunto de ideias dissidentes. Enquanto uma corrente heterodoxa tem um conjunto de princípios aceitos pelo grupo que a forma como alternativos ao mainstream de determinado tempo, a dissidência não precisa necessariamente ter um grupo que concorda com princípios comuns e, talvez, principalmente, muito menos com um rótulo para sua autodesignação. Um dissidente ou grupo deles podem ser dissidentes em alguns princípios, mas concordar e trabalhar em sua pesquisa dentro do mainstream. ${ }^{1}$

Uma dessas correntes heterodoxas é o pós-keynesianismo. Ela é quase exclusivamente uma abordagem da economia voltada aos problemas da macroeconomia; porém, define o que é o pós-keynesianismo não é trivial. $\mathrm{Na}$ literatura, são longas as discussões sobre este assunto, tanto entre os que se declaram pós-keynesianos, quanto entre os pesquisadores que se encontram em seu entorno. Dentro dessas controvérsias, o presente artigo retoma a discussão que busca definir o pós-keynesianismo, mas considerando a questão a partir de um novo ângulo, o da análise cientométrica. $\mathrm{Na}$ verdade, para além disso, essa análise quantitativa aplicada ao nosso objeto parte de conceitos da filosofia da linguagem. Mais especificamente, adota-se a ideia de "finitismo de significados" sugerida por Klaes (2004), que será explicada na subseção 3.2.

Nosso estudo vale-se da chamada análise de Co-word, metodologia apontada por Klaes $(2004,369)$ como uma das possíveis ferramentas para se obter o significado de um termo através da ideia do finitismo de significados. Tal método consiste na representação gráfica do contexto em que determinado termo - no caso "Post Keynesian" - ocorre em um conjunto de textos. No presente trabalho, esse conjunto é formado por periódicos acadêmicos da área de economia. A hipótese que sustenta esta aborda-

1 Aqui, mainstream está sendo utilizado no sentido dado por Colander, Holt e Rosser Jr. (2004), expandido, posteriormente, por Dequech (2007). Basicamente, a definição diz que mainstream é a economia praticada pelos grandes centros, predominantemente norte-americanos, de pesquisa. Ela também inclui o que é praticado nos centros menores de educação e pesquisa que reproduzem o conhecimento daqueles grandes centros. 
gem é a de que, ao publicarem em periódicos acadêmicos, os cientistas estariam, de fato, delineando o significado da expressão dentro de um contexto específico - o da comunidade científica dos economistas. Desse modo, podemos dizer em síntese que o mapa de Co-word, produto final da referida análise, é uma representação gráfica do significado da expressão pós-keynesianismo em um contexto social relevante.

No que diz respeito a sua estrutura, o presente artigo encontra-se dividido em cinco seções, incluindo esta introdução. Na seção 2 apresenta-se uma breve história de como sugiram a rede social e as instituições pós-keynesianas. Na seção 3 faz-se uma exposição do referencial teórico que dá suporte à análise empreendida neste trabalho e é apresentado o método de mapeamento empregado para gerar os mapas de Co-word. Na seção 4 são apresentados e discutidos os resultados obtidos, aos quais seguem, seção 5 , alguns comentários finais a guisa de conclusão.

\section{Uma breve história do pós-keynesianismo}

Levando em consideração que nossa definição de pós-keynesianismo baseia-se especialmente no fato de que uma comunidade de cientistas define a expressão ao usá-la, a história que segue enfatiza a construção de uma rede de pesquisa e de propagação de ideias às quais, em geral, os economistas referem-se como pós-keynesianas.

\subsection{O pós-keynesianismo de 1971 a 1977: o começo}

Embora não seja possível falar em uma corrente de pensamento econômico pós-keynesiana antes da década de 1970, em especial porque não existia um grupo específico de economistas que se (auto)identificassem com esse nome, a história que vai desembocar na formação da rede em torno da perspectiva começa nos anos 1960. Nesta década, Joan Robinson (19031983) viajou várias vezes aos Estados Unidos para apresentar conferências sobre diversos temas, dentre eles, sobre aquilo que via como as principais falhas da teoria macroeconômica neoclássica (King 2002, 240; Mata 2004, 242 e 250; Lee 2009, 78-80). 
Depois dessas viagens, em dezembro de 1971, Robinson ministrou a conferência que pode ser tratada como uma espécie de inauguração formal do pós-keynesianismo. Convidada por John Kenneth Galbraith, na época presidente da American Economic Association, Robinson apresentou a principal palestra do encontro. ${ }^{2}$ Sua exposição reclamava uma profunda releitura de Keynes. Ela acusava o mainstream de "ter colocado Keynes para dormir” (Robinson 1972, 4; King 2002, 121-125; Lee 2009, 81-82).

Nos bastidores do evento, em um encontro planejado por Alfred Eichner, Robinson conversou com vários economistas que compartilhavam sua insatisfação com o mainstream. Nessas conversas, ela sugeriu que a empreitada de reconstrução da teoria econômica que acabara de propor se chamasse pós-keynesianismo. Tal nome, entretanto, não foi prontamente aceito, dada a grande diversidade de visões entre seus ouvintes. Na verdade, talvez a única coisa que os unia naquele momento era o desejo de superar o que identificavam como problemático na corrente dominante (eram apenas dissidentes, portanto). Contudo, essa insatisfação foi suficiente para impulsionar uma série de ações para constituir uma rede de cooperação com vistas a propagar e desenvolver ideias de superação das limitações do mainstream no sentido do que viria a ser o pós-keynesianismo (King 2002, 121-125; Lee 2009, 81-82).

A empreitada foi encabeçada por Eichner. A primeira medida tomada por ele foi coletar os endereços dos participantes, formular e enviar-lhes uma carta com perguntas sobre qual seriam suas visões sobre uma possível alternativa ao mainstream. Posteriormente, com as respostas em mãos, ele redigiu e enviou-lhes uma segunda carta contendo as opiniões de todos e pedindo-lhes que indicassem outros economistas para serem incluídos na discussão. Desse modo, já em janeiro de 1972, teve início a circulação de um boletim informativo sobre as atividades do grupo. Passo fundamental para conectar os economistas que buscavam uma alternativa ao mainstream. Um segundo passo importante dado por Eichner foi arranjar para o grupo um espaço nos encontros da Union for Radical Political Economics. (Lee 2009, 80-83).

2 A principal palestra do encontro anual da American Economic Association é a Richard T. Ely Lecture, uma homenagem ao fundador da associação nos anos 1880 . 
Das poucas seções idealizadas por Eichner na Union for Radical Political Economics, a última aconteceu em 1974, e seu título foi Alternative Approches to Economic Theory. Nela, Eichner apresentou uma prévia do artigo An Essay on Post-keynesian Theory: A New Paradigm in Economics que seria publicado em 1975 no Journal of Economic Literature. A nova abordagem da teoria econômica, entretanto, não agradou parte considerável dos marxistas, que formavam a maioria dos associados à Union for Radical Political Economics. Todavia, durante os anos seguintes, a Union for Radical Political Economics continuou aceitando artigos de economistas pós-keynesianos para suas sessões. De acordo com Lee $(2009,84)$, isso foi extremamente importante para a história e a constituição dessa nova corrente, pois tais reuniões eram um dos poucos lugares nos quais os póskeynesianos podiam trocar ideias com seus colegas de profissão.

O fruto mais notável do esforço encabeçado por Eichner para construir a rede social pós-keynesiana foi, sem dúvida, o seu artigo no Journal of Economic Literature intitulado An Essay on Post-keynesian Theory: A New Paradigm in Economics. Depois de anos participando de eventos com economistas insatisfeitos com o mainstream e trocando cartas sobre uma possível alternativa com diversos deles, Eichner encontrava-se preparado para escrever um trabalho que apresentasse à comunidade acadêmica as características fundamentais do pós-keynesianismo. Todavia, não queria fazer isto sozinho e, assim, com Jan Kregel como coautor e com a ajuda de Robinson, Paul Davidson, Geoffrey Harcourt e Luigi Pasinetti, ele deu um passo importante para a consolidação do nome "Post keynesian" para designar a nova abordagem, publicando seu artigo seminal na edição de dezembro de 1975 no Journal of Economic Literature (Lee 2009, 85; King 2002, 130; Eichner e Kregel 1975, 1293).

Eichner e Kregel começam o artigo já deixando claras suas pretensões, pois na introdução escrevem: "This generalization may be said to represent, in Thomas Kuhn's sense, a new paradigm [...].[...] post-keynesian theory has the potential for becoming a comprehensive, positive alternative to the prevailing neoclassical paradigm" (Eichner e Kregel 1975, 1293-1294). Outra preocupação dos autores era explicar, já na primeira nota de rodapé, que o nome escolhido para a nova corrente de pensamento, "Post keynesian", não deveria ser interpretado como um desprezo às contribuições de outros economistas, tais como Micheł Kalecki e Piero Sraffa (Eichner e Kregel 1975, 1293). 
Em síntese, a publicação deste artigo e o seminário de Robinson de 1971 são dois grandes marcos da história do pós-keynesianismo (Lee 2009, 82). ${ }^{3}$

\subsection{O pós-keynesianismo de 1978 a 1988: a construção do suporte institu- cional}

Por volta de 1977, a rede social pós-keynesiana já estava suficientemente desenvolvida nos Estados Unidos para tornar possível a fundação de uma revista acadêmica. Foi Sidney Weintraub que, percebendo isto, conseguiu o suporte financeiro necessário junto à Universidade de Rutgers, através do apoio de Davidson, de modo que a primeira edição do Journal of Post Keynesian Economics (doravante JPKE) veio a público em 1978 (Lee 2009, 87-89). Note a importância que deram ao nome da abordagem, destacando-o já no título da publicação.

O primeiro editorial apresentava "uma declaração de propósitos", afirmando que o pós-keynesianismo seguia o esteio de vários economistas importantes, tais como: Smith, Ricardo, Marx, John Stuart Mill, Jevons, Marshall, Keynes, Robinson, Kaldor, Kahn, Kalecki, Abba Lerner, Galbraith e Minsky. ${ }^{4}$ Sobre o termo "pós-keynesianismo", escreveram que: "The term 'Post Keynesian' will thus be broadly interpreted, spotlighting new problems and revealing new theoretical perspectives" (Journal of Post Keynesian Economics 1978, 7). Em nossa opinião, isso quer dizer que o JPKE nascia eclético, declarando-se aberto a várias visões teóricas diferentes (Journal of Post Keynesian Economics 1978, 3-7; O'Hara 2003, 215-6). Todavia, isso não significa que o JPKE permaneceu completamente aberto a todas estas visões ao longo dos anos. O falecimento de Weintraub (1983) foi um ponto de transição para o periódico. Ao se tornar o principal editor, Davidson intensificou suas críticas às ideias de cunho sraffiano e kaleckiano, consideradas até então, por Weintraub, como parte do pós-keynesianismo (O’Hara 2003, 216). Mas, apesar desse foco mais restri-

3 É interessante, entretanto, observar que enquanto nos Estados Unidos, ao longo da década de 1970, se constituía uma rede social pós-keynesiana, graças principalmente ao trabalho de Eichner, na Inglaterra tal fenômeno não ocorreu na mesma época (Lee 2009, 83, 86, 136 e 143; King 133).

4 É interessante notar como os pós-keynesianos, assim como fizeram outras abordagens em economia, vão reivindicar uma longa tradição para si mesmos. Isso, claramente, vai no sentido da reinvenção da tradição sugerida por Arida (1996). De modo específico, Mata (2004) nota que entre os pós-keynesianos a reconstrução da história do pensamento econômico com vistas a defender sua abordagem é um expediente que pode ser observado recorrentemente nos trabalhos dos economistas ligados à corrente. 
to, o periódico definitivamente foi se convertendo na principal revista da corrente, contribuindo sobremaneira para consolidar o uso do termo "Post Keynesian" para se referir à nova abordagem (O'Hara 2003, 216).

Além de apoiar o JPKE, a Universidade de Rutgers passou a contratar vários professores ligados ao pós-keynesianismo. Em 1977, Rutgers contratou Jan Kregel. Na sequência, em 1978 e 1980, respectivamente, começaram a lecionar lá, Nina Shapiro e Alfred Eichner (Lee 2009, 89 e 93). Além disso, outras três revistas acadêmicas heterodoxas publicavam material póskeynesiano, a Review of Radical Political Economics, o Journal of Economic Issues e a Review of Social Economy (Lee 2009, 90-92).

$\mathrm{Na}$ Inglaterra, a constituição da rede social e do suporte institucional foi mais lento. Algo semelhante só surgiria em 1988 com a fundação do PostKeynesian Economics Study Group articulado por Phillip Arestis e Victoria Chick. Mesmo assim, quem estudasse a corrente em 1988 observaria uma rede social e de suporte institucional relativamente bem desenvolvidas nos Estados Unidos e, em menor grau, na Inglaterra (Lee 2009, 136-143; King 2002, 139; Hayes 2008, 298).

\subsection{O pós-keynesianismo depois de 1988}

Embora a Universidade de Rutgers tenha ficado conhecida como um centro pós-keynesiano entre 1977 e 1988, nem tudo corria bem para Davidson, Eichner e seus companheiros naquela instituição. A unificação de diversos departamentos, levada a cabo pela administração da universidade em maio de 1981, fez com que o ambiente favorável ao desenvolvimento do póskeynesianismo se deteriorasse rapidamente. Kregel deixou Rutgers depois de ter sido designado para dar aulas de contabilidade. Shapiro teve seu tenure negado. Após ter sido afastado da disciplina de macroeconomia do curso de pós-graduação, Davidson foi para a Universidade do Tennessee, levando consigo o JPKE. Eichner foi o único a permanecer em Rutgers até seu passamento, em 1988. Em síntese, no final da década de 1980, o suporte da Universidade de Rutgers à nova corrente tinha se dissolvido completamente (Lee 2009, 94). 
A rede social pós-keynesiana, entretanto, continuou crescendo através das revistas já fundadas e, principalmente, através dos estrangeiros que, depois de concluírem seus cursos de pós-graduação com professores pós-keynesianos americanos e britânicos, passaram a disseminar as ideias da corrente em outros países. (King 2002, 139-159; Paula e Ferrari Filho 2010, 248254; Lee 2009, 94; Lee 2009, 92 e 94).

Em suma, é inegável que a revolução conclamada por Robinson não vingou. Isso ainda que, ao olhar para a história da corrente durante as décadas de 1990 e 2000, seja possível observar o pós-keynesianismo como uma corrente ativa em que muitos economistas estavam atuando. Mas, em comparação com o mainstream, ela configura-se pequena e longe de se tornar dominante (Lee 2009, 95-96; Lee 2002, 285; King 2002, 135 e 259-260).

\section{Em busca da definição de pós-keynesianismo: as controvérsias da literatura e um método para encontrar uma definição}

Como acontece com outras correntes do pensamento econômico, e mesmo com várias expressões comumente utilizadas pelos economistas, é difícil chegar a uma definição unívoca do termo "Post Keynesian". Sendo assim, essa seção discute as delimitações do pós-keynesianismo já sugeridas pela literatura da própria escola, bem como as abordagens de Klaes (2004) e de Dachs et al. (2001), a partir das quais se construiu a metodologia da análise aqui apresentada.

\subsection{O pós-keynesianismo na literatura pós-keynesiana}

Em 1988, Hamouda e Harcourt (1988, 2-16) identificaram três subgrupos de pós-keynesianos. (1) Os pós-keynesianos americanos ou pós-keynesianos fundamentalistas. Este grupo partiria do Treatise on Money para compreender melhor a Teoria Geral do Emprego do Juro e do Dinheiro (doravante simplesmente Teoria Geral) e teria como principais representantes Weintraub, Davidson e Minsky. (2) Os neo-ricardianos ou sraffianos. Seriam aqueles que buscariam interpretar Keynes sob o prisma da tradição clássica, utilizando principalmente as ideias de Marx. Seus principais representantes seriam Sraffa, Garegnani e Pasinetti. E, finalmente, 
(3) os economistas de tradição kaleckiana-robinsoniana. Esses seriam os que leem a Teoria Geral à luz das adaptações de matiz marxista realizadas por Kalecki e Robinson.

Nessa mesma época, a inclusão dos sraffianos no grupo começou a ser questionada. A controvérsia foi desencadeada, em boa medida, pela redescoberta do Treatise on Probability de Keynes. Esse tratado foi publicado pela primeira vez em 1921, mas permaneceu em larga medida esquecido durante a maior parte do século XX. É neste livro que Keynes mostrava a incerteza radical como um elemento inultrapassável da realidade econômica. Assim, quando os seguidores do economista britânico reconheceram esse tipo de incerteza como ponto fundamental a partir do qual interpretar a obra de Keynes, transformando o Treatise on Probability num tratado ontológico da economia keynesiana, as abordagens que não aceitavam ou mesmo que não enfatizavam a incerteza radical como fundamento da realidade econômica não poderiam ser consideradas parte da reinterpretação de Keynes proposta pelo pós-keynesianismo (Mongiovi 2003, 318; King 2002, 192-197). Pode-se dizer que essa posição mais estrita é esposada principalmente pelo grupo de pós-keynesianos fundamentalistas.

O grande trabalho histórico de John King, publicado em 2002, A History of Post Keynesian Economics since 1936 adota uma postura bem mais aberta a respeito da delimitação do pós-keynesianismo. Na obra, consciente da necessidade de se ter uma definição de pós-keynesianismo que lhe possibilitasse escrever uma ampla história da corrente, King (2002, 5) admite entre os pós-keynesianos todos aqueles que se identificam dessa maneira. Dessa forma, ele adota como critério de inclusão a autodefinição. No mesmo sentido, Marc Lavoie, outro importante expoente do pós-keynesianismo, também acredita que o pós-keynesianismo deve permanecer largamente definido. Segundo ele, o pós-keynesianismo é capaz de conter os três subgrupos apontados por Hamouda e Harcourt (1988), sem exclusões (Lavoie 2005, 374-375; Lavoie 2009a, 19-24).

Adicionalmente, é comum os pós-keynesianos aproximarem-se do institucionalismo, da economia evolucionária e do marxismo (King 2002, 221239; Lavoie 2009a, 1). Certamente, para os fins deste trabalho, essas interações com outras escolas heterodoxas de pensamento são complicadores para a tarefa de definir uma regra ou um conjunto de premissas comuns capazes de delimitar com clareza o que é o pós-keynesianismo (Esposito 2013, 13). 
Uma opinião importante sobre a amplitude do pós-keynesianismo é a da metodologista Sheila Dow (2003). Para ela, esta dificuldade de agregação é uma característica própria de várias correntes do pensamento econômico, em especial das heterodoxas. Em seus trabalhos sobre metodologia da economia, Dow conceitua as bases ontológicas e metodológicas do pós-keynesianismo como alicerçadas no que chama de "modo de pensar babilônico". Este termo, babilônico, é usado por Dow (2003, 12 e 14) para designar uma ontologia que entende e estuda o sistema social como um "sistema aberto". Em suas palavras: "According to the Babylonian approach, there is no single logical chain from axioms to theorems; but there are several parallel, interwined, and mutually reinforcing sets of chains, such that no particular axiom is logically basic" (Dow 2003, 11). Este modo de pensar implica imprecisão na definição das escolas de pensamento, o que, ao contrário do que podemos imaginar, não deveria ser encarado como algo negativo. Salienta Dow $(2003,13):$ "Indeed vagueness of categories is seen to have the benefit of adaptability within a changing environment [...]". 5

Levando em conta que a imprecisão é um aspecto de certo modo positivo, e em vista das controvérsias na definição do termo, oferecemos, abaixo, em maior detalhe, uma metodologia para encontrar outra definição que leve em conta a construção social e histórica do significado do pós-keynesianismo.

\subsection{Um método para definir o pós-keynesianismo}

Para Dow, uma das correntes que compartilha com o pós-keynesianismo o modo de pensar babilônico é a economia evolucionária. Pode-se dizer, até mesmo, que a definição da economia evolucionária é assunto ainda mais controverso e difícil que a do pós-keynesianismo. O artigo de Klaes (2004) tenta precisamente contornar a dificuldade de demarcação da economia evolucionária, destacando o que o autor considera as vantagens da imprecisão definicional.

Baseado na filosofia da linguagem, Klaes (2004) propõe o finitismo de significados (meaning finitism) como princípio-guia para estudar o conteúdo

5 Neste artigo usam-se as palavras "imprecisão" e "imprecisa" como tradução do termo vagueness, empregado por Dow (2003) e Klaes (2004). Pensamos que essa tradução é melhor do que a palavra pouco usual em português brasileiro, "vaguidão". 
de expressões de difícil conceituação unívoca. Tal conceito tem suas raízes na filosofia de Ludwig Wittgenstein (1889-1951), segundo a qual, sendo a linguagem uma construção social, cada palavra ou expressão adquire, processualmente, o sentido que a sociedade, ao longo do tempo, lhe atribui. Essa ideia se opõe à significação do tipo determinista, de acordo com a qual uma regra fixa e não ambígua seria o princípio ideal através do qual deveríamos definir uma expressão. Ao contrário, para determinar o significado de uma expressão segundo a linha wittgensteiniana, é preciso olhar para o uso da expressão na sociedade ou, ao menos, em um subgrupo dela. No caso em tela, como a expressão é de caráter técnico, interessa fazer um recorte da sociedade, definindo a expressão dentro da comunidade científica de economia (Klaes 2004, 365).

A ideia de finitismo de significados é brilhantemente ilustrada por Klaes (2004, 364-365) através de um exemplo bastante simples. Imagine-se que dois indivíduos separam três objetos dentre vários que se encontram em uma sala. Ao escolher esses objetos, os dois indivíduos devem seguir uma lógica criada por eles mesmos, em consenso. Assim, estabelecem um conjunto de objetos: $\left\{\mathrm{O}_{1} ; \mathrm{O}_{2} ; \mathrm{O}_{3}\right\}$. Depois da primeira escolha, entra na sala um terceiro indivíduo a quem são apresentados os três objetos. O terceiro deve, a partir do primeiro conjunto de objetos, identificar um quarto objeto, $\mathrm{O}_{4}$, que possa ser adicionado ao grupo. Esse terceiro indivíduo deve procurar justificar cuidadosamente sua escolha, tentando encaixá-lo na lógica dos outros objetos, uma lógica que ele só conhece através do conjunto $\left\{\mathrm{O}_{1} ; \mathrm{O}_{2} ; \mathrm{O}_{3}\right\}$ (os primeiros dois indivíduos não revelam explicitamente a lógica ao terceiro). Esse quarto objeto é submetido ao crivo dos dois primeiros indivíduos e, uma vez que eles concordem, o objeto $O_{4}$ passa a fazer parte do conjunto. Nesse contexto, a inclusão do objeto $O_{4}$ depende, por um lado, da boa ou má disposição dos dois primeiros indivíduos em aceitar que $\mathrm{O}_{4}$ passe a fazer parte do conjunto inicial, e, por outro, do poder de persuasão do terceiro indivíduo. Essa seria uma determinação por concordância social (social agreement). Em continuação, o processo acabaria por definir uma classe de objetos através das concordâncias sociais sobre quais objetos fazem ou não parte do conjunto. 
Transferindo a lógica do exemplo para o nosso tema, podemos dizer que novas contribuições passam a figurar em uma corrente de pensamento através de uma espécie de negociação social, e não pela simples aplicação de uma regra estática. Por exemplo, quais são os artigos que os pares aceitam em determinado periódico? Esse processo é crucial para definir uma corrente de pensamento ou uma área do saber científico. ${ }^{6}$ Cabe pontuar, ainda, que tal processo de negociação, nas diversas ciências, é contínuo.

Klaes $(2004,366)$ pontua que o consenso nem sempre é facilmente obtido e, mais do que isso, muitas vezes, as tentativas de inclusão de objetos nas significações degeneram em conflitos. Assim sendo, na medida em que o uso das expressões "pós-keynesiano"/"pós-keynesianismo" são aceitos em determinado contexto, no caso, entre os periódicos especializados de economia, esse processo de construção social está em curso. Como o póskeynesianismo é uma expressão de uso pouco difundido fora dos círculos da academia econômica - ao contrário, por exemplo, de "marxismo" ou "liberalismo" - é razoável admitir que os periódicos científicos constituam um recorte relevante da sociedade em que se constrói o significado da expressão em foco. Neste contexto, conhecer o significado do termo que dá nome a uma corrente consiste em visualizar o conjunto de objetos a que determinada expressão é empregada. Mais ainda, e em síntese, de acordo com o finitismo de significados, uma corrente de pensamento pode ser vista como um aglomerado de temas (vagamente) interligados, e não necessariamente como um corpo teórico monolítico. Sendo assim, uma definição relevante do termo que nomeia uma corrente de pensamento surge como o resultado da compilação dos objetos a que a expressão é empregada pelos integrantes da comunidade acadêmica (Klaes 2004, 362-70).

Existem vários métodos para encontrar a acepção de um termo partindo da ideia do finitismo de significados. Dentre outros, Klaes (2004, 369-370) cita o método cientométrico utilizado por Dachs et al. (2001) para estudar a economia evolucionária: a análise de Co-word. Este método consiste na aplicação de tratamentos estatísticos a uma massa de textos para fazer com que o grau de coocorrência entre palavras seja representado por distâncias em um espaço bidimensional. Em síntese, tal método tem a capacidade de representar de forma gráfica o contexto em que determinado termo ocorre em uma dada literatura. A partir desta representação, é possível identificar

${ }_{6}$ Por exemplo, ao analisar o papel do American Journal of Sociology nos primeiros anos de sua existência, os quais contituíram o período em que a própria sociologia emergiu como campo científico, Andrew Abbott (1999) afirma que, de certo modo, esse periódico "criou" a sociologia americana. 
a estrutura de temas a que uma comunidade de pesquisadores se dedica, bem como descobrir quais são os principais termos que a comunidade acadêmica utiliza para definir, por exemplo, uma dada abordagem teórica. Aliás, isso é importante ressaltar: não é só a comunidade que esposa determinada corrente de pensamento que ajuda a formar a definição da mesma. O uso de determinada expressão por eventuais adversários ou cientistas não ligados à corrente também é formadora de significado. Dentro disso, assinalemos que, como se deseja aqui uma definição não unívoca, não determinista, socialmente determinada e que aproveite as vantagens de certa imprecisão, o próprio mapa de Co-word, resultado da análise proposta, pode ser considerado uma definição do que é o pós-keynesianismo.

\subsubsection{O Método de Co-word}

Dentre as diversas bases que reúnem artigos acadêmicos na área de Economia, escolhemos a Journal Storage (doravante JSTOR), para levar a cabo as análises presentes neste artigo. Essa escolha se deu porque ela disponibiliza gratuitamente todos os metadados das publicações em um formato compatível com o software usado nesse trabalho, além de reunir um grande número de periódicos antigos - fundamental para a construção do gráfico de frequência do uso do termo. A base Econlit, base utilizada por Dachs et al. (2001), conta com um número bastante reduzido de revistas e, consequentemente, possui um baixo número de artigos identificados como de economia. Já a JSTOR possui mais de 240 títulos de periódicos acadêmicos na área de economia e tem um número de artigos nessa área que supera 620.000. Isso a torna uma base representativa para a área. ${ }^{7}$

Para produzir a análise de Co-word foi utilizado o programa VOSviewer. O software em questão utiliza uma técnica específica para a elaboração dos mapas de Co-word, que compatibiliza alocação e "clusterização" de palavras, denominada "Mapeamento por Visualização de Semelhanças" (Visualization of Similarities Mapping Technique). No que segue, descrevemos suscintamente esta técnica. ${ }^{8}$

7 Duas possíveis alternativas a base JSTOR seriam a Web of Science e a Scopus, porém nenhuma das duas tem a preocupação histórica de reunir e tornar acessível ao usuário documentos antigos como a JSTOR.

8 A breve descrição das técnicas utilizadas pelo programa VOSviewer apresentada neste artigo foi construída com base nos seguintes artigos: Van Eck e Waltman (2011, 50-54), Waltman, Van Eck e Noyons (2010, 629-635), Van Eck e Woltman (2007, 299-306), Van Eck e Woltman (2010, 530-532). 
Dadas $n$ palavras relevantes e considerando que duas palavras quaisquer coocorrem quando aparecem juntas num mesmo documento, tem-se a força de associação entre as palavras $i$ e $j$ definida como: ${ }^{9}$

$$
s_{i j}=\frac{2 m c_{i j}}{c_{i} c_{j}}
$$

Onde, $s_{i j}$ é a força de associação entre as palavras $i$ e $j ; m$ é o número total de coocorrência entre todas as palavras; $c_{i j}$ é o número de vezes que a palavra $i$ coocorre com a palavra $j$; $c_{i}$ corresponde ao número total de coocorrências da palavra $i$ com outras palavras e $c_{j}$ ao número total de coocorrências da palavra $j$ com outras palavras. Em notação matemática, os termos acima são:

$$
c_{i}=\sum_{i \neq j} c_{i j} \quad \text { e } \quad m=\frac{1}{2} \sum_{i} c_{i}
$$

Assim, de acordo com (1), as palavras que aparecem em muitos documentos, mas poucas vezes juntas possuem uma força de associação, $s_{i j}$, baixa, enquanto palavras que aparecem em poucos documentos, mas sempre juntas, têm uma força de associação, $s_{i j}$, alta.

A partir de (1), monta-se uma matriz, $\boldsymbol{S}=\left(s_{i j}\right)$, que satisfaça as seguintes condições: $s_{i j} \geq 0, s_{i i}=0$ e $s_{i j}=s_{j i}$ para todo $i, j \in\{1, \ldots n\}$. Tal matriz recebe o nome matriz de semelhanças, pois cada um dos seus elementos denota uma "semelhança" existente entre duas palavras, ou seja, o fato de elas ocorrerem no mesmo documento.

As $n$ palavras relevantes são dispostas em um espaço euclidiano bidimensional, levando em conta esta matriz, e a isso se dá o nome de "mapa de Co-word". Neste mapa, a posição de cada palavra é representada por um vetor $\boldsymbol{x}_{i}=\left(x_{i 1}, x_{i 2}\right) \in \mathbb{R}^{2}$, de modo que o conjunto de todos esses vetores forma uma matriz $\mathrm{X},\left(\begin{array}{ll}n & \times 2\end{array}\right)$, que contém as coordenadas de todas as palavras. Estas coordenadas devem expressar o melhor possível a força de associação existente entre as palavras, de modo que as palavras que tem um $s_{i j}$ alto apareçam próximas e palavras com um $s_{i j}$ baixo sejam representadas distantes umas das outras.

9 Por palavras relevantes entendem-se substantivos e sequências de palavras, composta por substantivos e adjetivos. Para mais detalhes sobre como o VOSviewer seleciona tais palavras e sequências de palavras confira: Van Eck e Waltman $(2011,50)$. 
Para encontrar tais coordenadas, o método de Mapeamento por Visualização de Semelhanças propõe a minimização da soma ponderada do quadrado das distâncias euclidianas, sujeita a uma restrição que impeça soluções em que todas as palavras sejam alocadas em um mesmo ponto. Além disso, este método permite construir clusters de afinidade entre as palavras, facilitando, assim, a identificação de temas de pesquisa. Em notação matemática, o problema a ser resolvido é minimizar a seguinte função:

$$
E(\boldsymbol{X} ; \boldsymbol{S})=\sum_{i<j} s_{i j} d_{i j}^{2}-\sum_{i<j} d_{i j}
$$

Onde $d$ corresponde à distância euclidiana entre dois pontos, sendo no caso do mapa:

$$
d_{i j}=\left\|x_{i}-x_{j}\right\|=\left(\sum_{k=1}^{2}\left(x_{i k}-x_{j k}\right)^{2}\right)^{1 / 2}
$$

Enquando no caso do cluster, $d$ corresponde a seguinte regra de corte:

$$
d_{i j}=\left\{\begin{array}{lll}
0 & \text { se } & x_{i}=x_{j} \\
1 / \gamma & \text { se } & x_{i} \neq x_{j}
\end{array}\right.
$$

Quanto ao processo de clusterização, cabe salientar que se trata, simplesmente, de agrupar palavras de acordo com a força de associação existente entre elas. O número de clusters é determinado pelo valor atribuído a $\gamma$, denominado parâmetro de resolução. Quanto maior o valor atribuído pelo pesquisador a este parâmetro, maior é o número de clusters que serão obtidos. Segundo Van Eck e Waltman $(2013,14)$, devem-se testar vários valores até que sejam obtidos clusters que façam sentido do ponto de vista analítico, por inspeção visual.

Além dos processos de mapeamento e clusterização, o VOSviewer representa cada palavra presente no mapa de Co-word através de um círculo com tamanho proporcional ao número de artigos em que ela ocorre. $\mathrm{O}$ que constitui mais um dado integrado ao mapa. Em síntese, o mapa de Co-word, pela forma como é construído, permite identificar tanto a estrutura de temas a que os pós-keynesianos se dedicam, como descobrir quais são os principais termos que a comunidade acadêmica como um todo utiliza em conjunto com o pós-keynesianismo. Pensamos que esse processo emula o exemplo da adição de objetos apresentado acima para ilustrar o finistismo de significados. 


\section{Resultados e discussão}

Para cumprir o objetivo de melhor compreender o uso da expressão "Post Keynesian" entre os economistas acadêmicos, considerou-se oportuno dividir esta tarefa em dois passos. Primeiro, apresenta-se uma análise da ocorrência do termo ao longo dos anos nos periódicos de economia arrolados no JSTOR. Depois, em segundo lugar, apresenta-se a análise de Co-word propriamente dita juntamente com algumas considerações a respeito. ${ }^{10}$

\subsection{O uso do termo "Post Keynesian" ao longo dos anos}

A análise da frequência com que o termo "Post Keynesian" foi utilizado ao longo dos anos nos periódicos de economia arrolados na base JSTOR permite cotejar as variações na ocorrência do termo com a história da corrente encontrada na literatura e apresentada acima.

O Gráfico 1 mostra o percentual de artigos em que ocorre o termo "Post Keynesian", incluindo e excluindo o JPKE, em relação ao total de artigos publicados em revistas de economia, para cada ano, desde 1936 até 2012. Ao observá-lo, entretanto, vem à mente a seguinte pergunta: será que essa ocorrência percentual não estaria influenciada pela entrada e saída de revistas da base JSTOR - já que ao longo desse período, 76 anos, revistas científicas nasceram e morreram ou simplesmente deixaram de estar disponíveis nesta base? O Gráfico 2 mostra que, embora a entrada ou saída de revistas específicas - provavelmente heterodoxas - possa ter influenciado o formato da curva que vemos no Gráfico 1, isso não é verdade se consideramos essas entradas e saídas em seu conjunto. ${ }^{11}$

${ }^{10}$ King $(2002,10)$, a respeito do termo "Post Keynesian", afirma que existem quatro formas diferentes de escrevê-lo em inglês, são elas: Post-Keynesian, post-Keynesian, Post Keynesian e post Keynesian. Assim, embora haja diferenças no uso ou não da letra maiúscula no início de cada palavra, a controvérsia quanto à grafia deste termo concentra-se no que diz respeito ao uso ou não do hífen. Segundo Lee $(2009,82)$ e Lavoie $(2005,373)$, o hífen costuma ser empregado pelos economistas que estiveram mais fortemente ligados a Cambridge, enquanto o uso do termo sem hífen é defendido por Davidson e seus seguidores. Este último grupo prefere a grafia sem hífen para diferenciar sua abordagem da economia Neo-keynesiana (Neo-Keynesian), uma vez que este último termo foi usado como sinônimo de "post-Keynesian/Post-keynesian" durante a década de 1970. No entanto, esta controvérsia perdeu importância com o passar do tempo e, por volta dos anos 1980, como afirma Lee (2009, 82), "[...] the controversy had run its course and either name (although the "Post Keynesian" spelling was used most often) became generally accepted as representing the broad view of what constituted Post Keynesian economics".

${ }^{11}$ Analisando as datas de entrada e saída das revistas em que mais ocorre o termo "Post Keynesian" na base JSTOR, com exceção do JPKE, não parece que elas tenham influenciado o formato da curva 
Posto isso, passa-se agora à análise do Gráfico 1. Nele é possível identificar cinco períodos distintos.

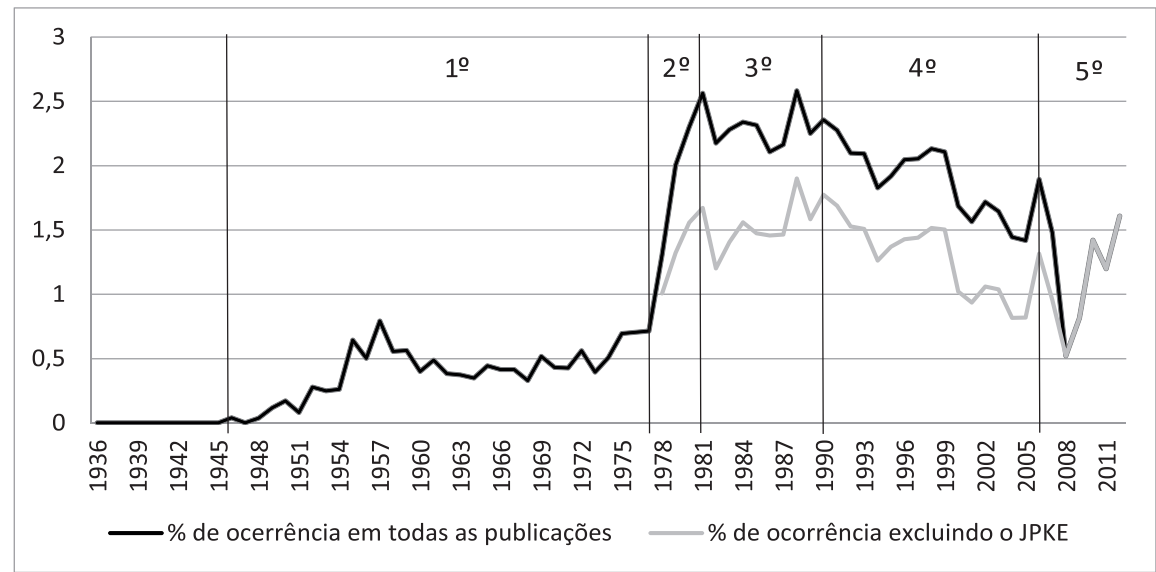

Gráfico 1 - JSTOR: frequência do termo "Post Keynesian" em \% de publicações em economia (1936-2012)

Fonte: JSTOR, gráfico elaborado pelos autores.

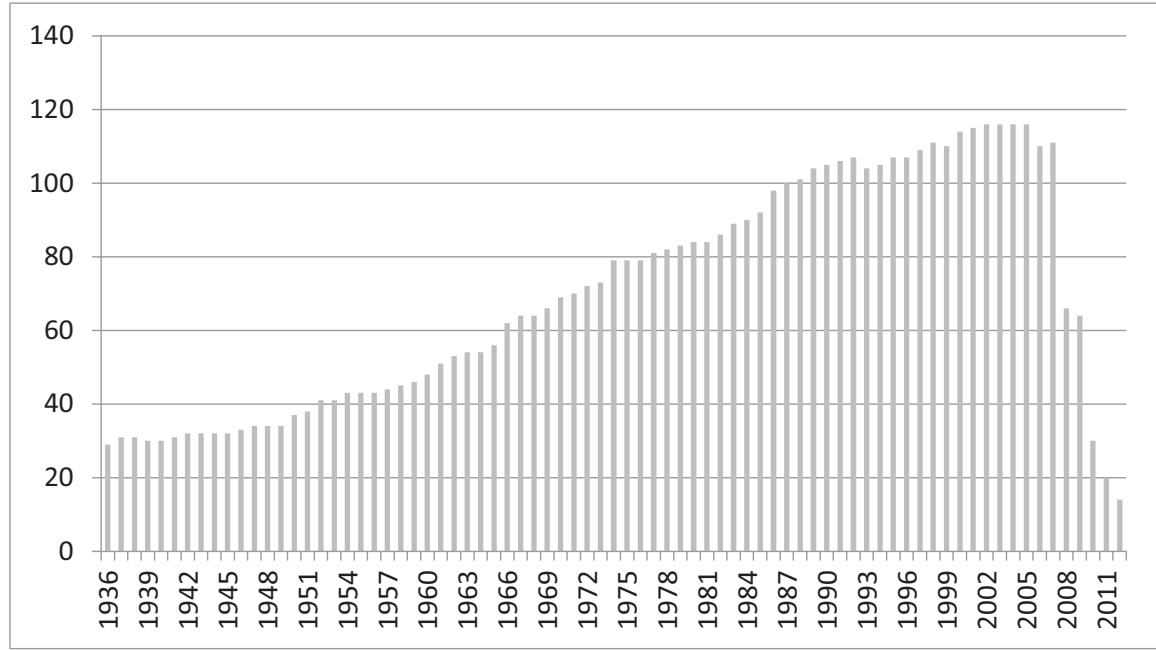

Gráfico 2 - JSTOR: Número absoluto de revistas classificadas como de economia (19362012)

Fonte: JSTOR, gráfico elaborado pelos autores.

plotada no Gráfico 1 - vide Tabela 1. Contudo, uma análise mais profunda e objetiva dessa questão envolveria rotular a priori as revistas contidas na base como ortodoxas ou heterodoxas, algo que demandaria regras estáticas de classificação, ou seja, que constitui uma prática contrária ao objetivo de obter uma definição através do finítimo de significados. 
O primeiro período vai do final da II Guerra Mundial até meados da década de 1970. Neste período, o termo "Post Keynesian" começou a ser empregado para designar os avanços no campo econômico que ocorreram cronologicamente depois de Keynes. Usava-se um sentido bastante simples para a expressão, que significava, tão somente, "depois de Keynes" e em decorrência do seu trabalho. Durante estas décadas, o termo foi usado de forma relativamente estável nas publicações de economia e, como salienta Lee $(2009,81-2)$, o mesmo era intercambiável com "neo-keynesian" e "neoclassical keynesianism". Dois fatos ilustram bem a ausência de diferenciação entre estes termos. Um deles é o uso de "neo-Keynesian" por Davidson em seu livro Money and the Real World, em 1972, para se referir à abordagem que estava apresentando. O outro é o emprego de "Post Keynesian” por Paul Samuelson (1915-2009), em 1948, em seu famoso livro Economics. Enquanto o primeiro seria um expoente da abordagem pós-keynesiana propriamente dita, Samuelson é reconhecido como um dos principais autores do que viria a ser a síntese neoclássica baseada nas ideias de Keynes.

A conferência proferida por Joan Robinson durante o encontro da American Economic Association, em 1971, e, especialmente, o artigo publicado por Eichner e Kregel, em 1975, marcam o momento em que termo "Post Keynesian" começa a ser usado para designar um grupo especifico de pesquisadores - como foi visto na subseção 2.1. Contudo, é apenas depois da fundação do JPKE, em 1978, que tal termo passa a ser usado mais intensivamente na literatura - e, é claro, nos periódicos pesquisados. Isso assinala o início do segundo período identificado no Gráfico 1. Este período, relativamente curto, corresponde a uma fase de rápido crescimento da corrente, marcando o tempo em que ela está construindo seu próprio suporte institucional principalmente nos Estado Unidos, tema da subseção 2.2. É precisamente neste período que se consolida o uso do nome "Post Keynesian" para se referir à nova corrente de pensamento. ${ }^{12}$

O terceiro período caracteriza-se por uma relativa estabilidade no número de ocorrências do termo "Post Keynesian" e diz respeito a toda a década de 1980. O fim do crescimento rápido reflete, provavelmente, a dificuldade que a corrente enfrentou para ganhar terreno. Pode-se dizer que, uma vez constituída sua rede social e suas instituições de suporte, o pós-keynesianismo começa a se recolher em algo como um "gueto" científico, para empregar a expressão utilizada por King $(2002,135)$.

12 Essa constatação vai na direção do que afirmamos acima na nota 6, com base em Abbott (1999). 
Após esse ínterim de estabilidade, entretanto, segue-se um quarto estágio em que a ocorrência vai caindo lentamente, consequência, provavelmente, da dificuldade de atrair novos pesquisadores para a abordagem - consequência da marginalidade, do "gueto" em que a corrente estava localizada. Lee, no seu estilo caracteristicamente contundente, em 1995, interpreta tal queda como um sinal eminente do fim do pós-keynesinismo: "[...] there literally will be no Post Keynesian economists around to teach Post Keynesian economics when the present group of Post Keynesians eventually retires by 2020." (Lee 1995, 1).

Já a queda abrupta que se observa de 2007 para 2008, deve-se ao fato do JPKE não estar mais disponível na base JSTOR depois deste ano. Entretanto, é interessante notar que, mesmo sem levar em conta a principal revista da corrente, há um aumento considerável no número de ocorrências do termo "Post Keynesian" depois da crise econômica de 2008, ou seja, no quinto ${ }^{13}$ período identificado no Gráfico 1. Tal crise guarda certa semelhança com um dos cenários previstos por King (2002, 257), em que o pós-keynesianismo poderia se tornar a corrente dominante como consequência de uma nova revolução científica desencadeada por uma possível crise econômica mundial. Este vaticínio, porém, não se materializou. O pós-keynesianismo permanece uma corrente marginal de pensamento econômico, embora possa ter crescido um pouco, como sugere o aumento na frequência com que aparece o termo "Post Keynesian" nas publicações científicas recentes (Lavoie 2014, 2009b 19).

Uma interpretação alternativa para os períodos de estabilidade, queda e retomada - respectivamente terceiro, quarto e quinto - é que tais períodos se explicam, não pela entrada dos pós-keynesianos em um gueto como afirmam King $(2002,135)$, mas pelo amadurecimento da própria abordagem. À medida que a abordagem foi se tornando mais desenvolvida, fazer referência a ela só seria necessário quando se estivesse dialogando com pesquisadores que desconhecessem o pós-keynesianismo. Esta interpretação, embora seja plausível do ponto de vista dos dados, não parece ser a mais popular entre os estudiosos da história da corrente, nem entre seus representantes. Ao menos é o que sugerem os trabalhos de King (2002, 135), Lee (2003, 285), Davidson (2003-4, 270), Lavoie (2014, 2009b, 19). Esses autores, embora não neguem que o pós-keynesianismo amadureceu,

${ }^{13}$ Cabe pontuar que, embora a análise apresentada aqui sobre o quinto período do Gráfico 1 seja plausível, ela deve ser considerada com cautela, pois após 2006, o número de revistas disponíveis na base JSTOR cai consideravelmente tal como mostra o Gráfico 2. 
mostram-se preocupados pelo futuro da corrente, corroborando explicita ou tacitamente a interpretação de que a corrente tem dificuldade para atrair novos adeptos.

A análise do Gráfico 1 suscita, ainda, algumas questões interessantes; a primeira delas é quão concentradas estão as ocorrências do termo "Post Keynesian" nas revistas que fazem parte do suporte institucional da corrente? Ou, usando novamente as palavras de King $(2002,135)$, quão fechados estão os pós-keynesianos em seu gueto? A Tabela 1 mostra que, embora as ocorrências entejam concentradas principalmente em revistas como o próprio JPKE e o Journal of Economic Issues, a voz dos pós-keynesianos parece ser ouvida também fora do aparato institucional puramente heterodoxo. Ao menos é o que indica o fato do Journal of Economic Literature ser a segunda revista em que o termo "Post Keynesian" mais ocorre entre os periódicos disponíveis na base JSTOR. Assim como o fato de o termo ocorrer na The American Economic Review com a mesma frequência que aparece na Review of Social Economy. Em outras palavras, embora a maior parte da literatura pós-keynesiana seja produzida por poucas revistas, isso não significa que a corrente dominante desconsidera completamente o que tais economistas dizem. ${ }^{14}$

Tabela 1 - JSTOR: Porcentagem de Ocorrência do termo "Post Keynesian" Por Revista 1936-2012)

\begin{tabular}{lc}
\hline Journal of Post Keynesian Economics (1978-2007) & $28 \%$ \\
Journal of Economic Literature (1969-2012) & $18 \%$ \\
Journal of Economic Issues (1967-2010) & $8 \%$ \\
The Economic Journal (1891-2011) & $5 \%$ \\
The American Economic Review (1911-2012) & $3 \%$ \\
Challenge (1952-2009) & $3 \%$ \\
Review of Social Economy (1942-2011) & $3 \%$ \\
Eastern Economic Journal (1974-2011) & $3 \%$ \\
Southern Economic Journal (1933-2012) & $3 \%$ \\
International Journal of Political Economy (1987-2009) & $2 \%$ \\
* Outras 105 revistas em que o termo ocorre menos de 1\% & $24 \%$ \\
\hline Total & $100 \%$ \\
\hline
\end{tabular}

Fonte: JSTOR, tabela elaborada pelos autores.

${ }^{14}$ Uma importante revista identificada como pós-keynesiana é o Cambridge Journal of Economics - tal como foi apresentado na seção 2. Contudo, essa revista não se encontra disponível na base JSTOR, bem como algumas outras revistas comumente apontadas como heterodoxas, tais como a Review of Radical Political Economics, Review of Political Economy, etc. 


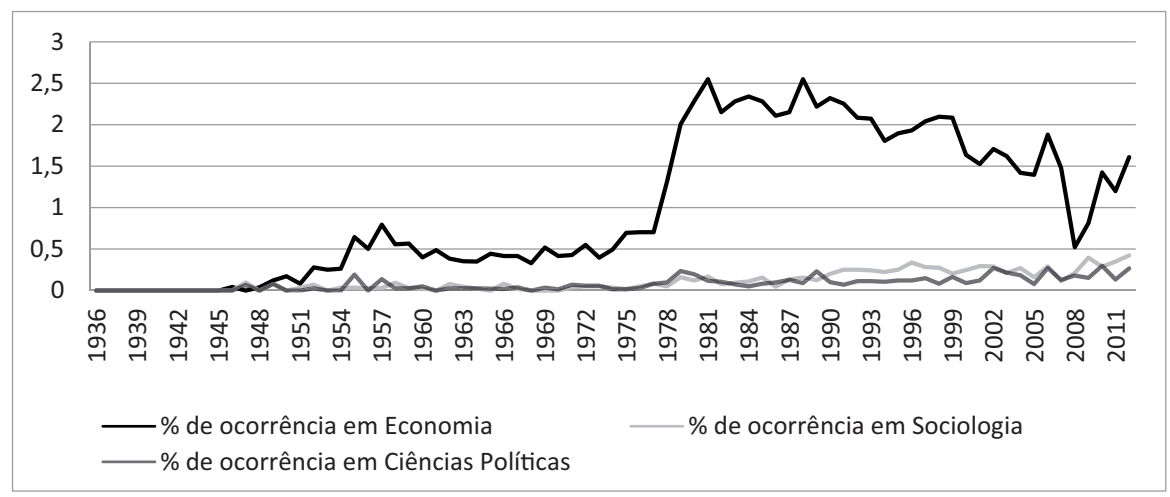

Gráfico 3 - JSTOR: Frequência do Termo "Post Keynesian" em \% de publicações em outras áreas do conhecimento - Sociologia e Ciências Políticas (1936-2012)

Fonte: JSTOR, gráfico elaborado pelos autores.

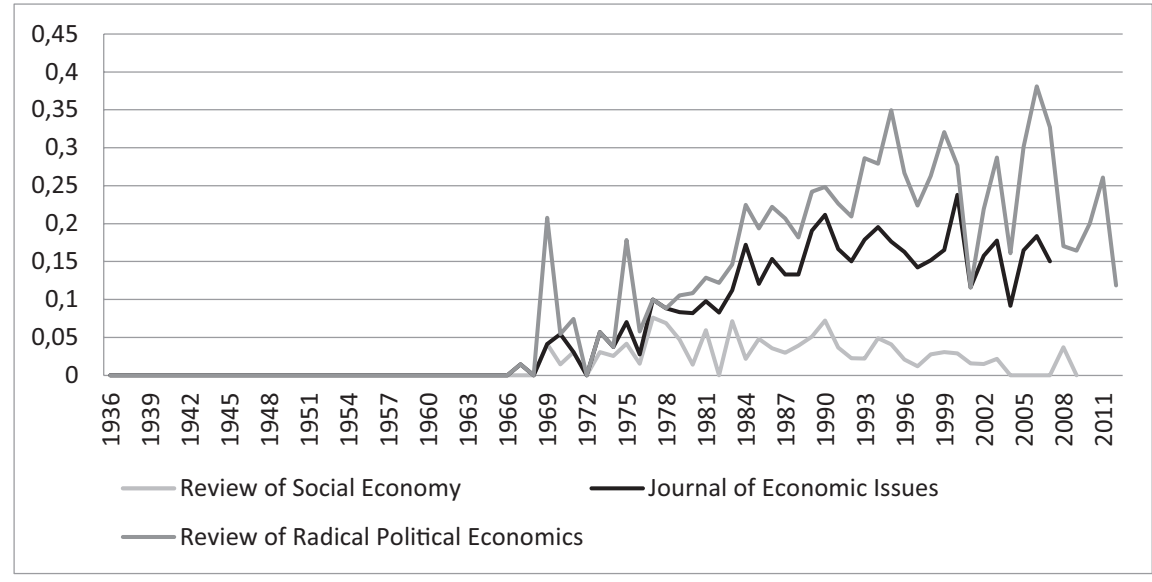

Gráfico 4 - JSTOR: Frequência do Termo "Post Keynesian" em \% de artigos publicados por revistas Heterodoxas (1936-2012)

Fonte: JSTOR, gráfico elaborado pelos autores.

Outra pergunta interessante de se fazer é: será que durante os anos 1990 e a maior parte dos anos 2000 a queda que observamos no número de ocorrências do termo pode ser consequência da migração desta abordagem para outros campos do conhecimento, tal como sugere King (2002, 58-9)? Ao analisar o Gráfico 3, que traz o percentual de ocorrência do termo "Post Keynesian" em Sociologia e nas Ciências Políticas, não há indício de que isto esteja acontecendo. Neste ponto, talvez Davidson (2003-4, 270) tenha 
razão, migrar para outras áreas do conhecimento seria como admitir um suposto fracasso da abordagem pós-keynesiana, algo que a maior parte dos pesquisadores desta corrente pode não estar disposta a fazer.

Por fim, uma última pergunta interessante a ser levantada é: como evoluiu, ao longo dos anos, o suporte dado ao pós-keynesianismo por outras revistas heterodoxas, tais como Review of Radical Political Economics, Journal of Economic Issues e Review of Social Economy? O Gráfico 4 parece indicar que, embora haja uma grande variação no número de ocorrências do termo "Post Keynesian" nestas revistas, de ano para ano, existe, do início da década de 1980 até o começo dos anos 2000, um aumento percentual no número de ocorrências do termo. Já durante os anos 2000, tal percentual se manteve relativamente estável, não apresentando nem tendência a crescer, nem a diminuir.

Em síntese, o mais importante a se reter desta seção é: considerar que o termo "Post Keynesian" passa a ser usado para designar um grupo específico de economistas só é claro depois que ele começa a ser amplamente utilizado na literatura, o que ocorre em 1978 com a fundação do JPKE. E nisso, acontece algo surpreendente, pois o JPKE marca o início do uso do termo com maior frequência, entretanto, ele não é crucial na variação das ocorrências. Aparentemente, o lançamento da revista não somente significou um avanço da corrente dentro das páginas da mesma, mas o pós-keynesianismo passa a estar presente em outras publicações. É um efeito interessante se o mesmo for creditado ao surgimento da revista. Mas, é claro, deve-se considerar que não somente foi o lançamento da revista o responsável pelo observado, ela deve ter sido mais propriamente um catalisador.

\subsection{O que é Pós-Keynesianismo de acordo com a análise de co-word?}

A análise de Co-word, tal como foi visto na seção 3, é utilizada aqui para captar o significado de "Post Keynesian" a partir do contexto em que os economistas empregam este termo. Desse modo, torna-se premente adotar como princípio intervir o mínimo possível durante o processo de obtenção dos mapas de Co-word, permitindo que o significado do termo emerja, de fato, do uso que o grupo social relevante faz dele. 
O processo empreendido ao longo deste artigo para obter o mapa de Co-word apresentado na Figura 1 pode ser descrito em quatro passos. O primeiro foi obter os metadados de todos os artigos classificados como econômicos pela JSTOR e que continham o termo "Post Keynesian" em qualquer lugar do texto, o que totalizou 5.725 artigos. O segundo foi descartar todos os artigos anteriores a 1978, pois antes disso o uso do termo "Post Keynesian" para designar uma corrente específica de pensamento econômico era pouco difundido, como mostrou o Gráfico 1. O terceiro passo correspondeu à decisão de utilizar apenas os resumos dos artigos para a elaboração do mapa, isto porque neles as palavras estão de fato em um contexto literário, o que não acontece em outros metadados, tais como o título, as palavras-chave, etc. O quarto foi reunir os termos equivalentes "Post Keynesian economics", "Post Keynesian approach", "Post Keynesian theory" e "Post Keynesian", sob este último, ou seja, na Figura 1 todos eles aparecem computados como "Post Keynesian".

Outro aspecto que convém recordar antes de partir para a análise propriamente dita da Figura 1 é que, como foi sugerido acima, esta figura apresenta de modo visual um resumo de como os economistas utilizam linguístico-socialmente o termo "Post Keynesian". Em outras palavras, a Figura 1 é uma das definições possíveis do que é "Post Keynesian" através da ideia finitismo de significados, mais especificamente, uma definição cientométrica do que os economistas entendem por este termo. Pode-se encarar as expressões que aparecem no mapa de Co-word como os objetos negociados entre os economistas para ocorrerem no entorno da expressão "Post Keynesian". Da mesma forma, é de fundamental importância o corte das expressões em clusters - sinalizados pelas diferentes cores no gráfico. Isso indica que a negociação da entrada de objetos pode ser avaliada separando-os em conjuntos discretos que mostram subconjuntos de significados dentro do significado maior, "guarda-chuva". Ainda, mais detalhadamente, os diferentes clusters apontam áreas e aplicações em que os economistas que utilizam o termo atuam ou, ainda, os círculos de assuntos em que o uso do termo é feito.

Cabe pontuar ainda que o Mapeamento por Visualização de Semelhanças empregado pelo VOSviewer para a realização da análise de Co-word - por selecionar as palavras relevantes de forma automática (Van Eck e Waltman 2011, 50), uma limitação inerente ao método - trará sempre palavras que tomadas individualmente são incapazes de definir uma corrente de pensamento econômico, tais como econômica, política econômica, fiscal etc., 
porém, tais palavras são importantes para identificação dos clusters. Por isso - e também para manter o propósito deste artigo de intervir o mínimo possível nos resultados - não foi retirada nenhuma palavra identificada como relevante pelo método de Mapeamento por Visualização de Semelhanças.

泉 vosviewer

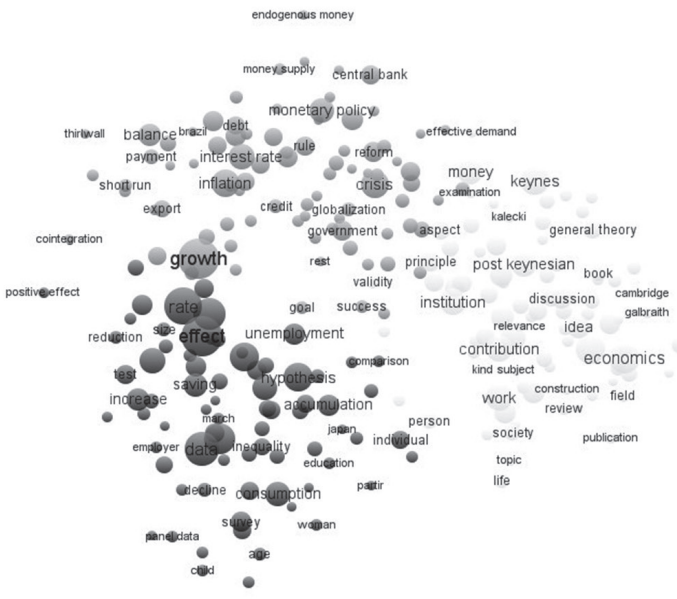

Figura 1 - Mapa de co-word para o termo Post Keynesian - incluindo todos os resumos que contém o termo de 1978 a 2012

Fonte: JSTOR, figura elaborada pelos autores.

Ao observar a Figura 1, é possível identificar três clusters e, pelas palavras que cada um contém, pode-se afirmar que se trata de três grandes áreas em que se divide a pesquisa da corrente pós-keynesiana ou dos economistas que citam, mesmo que criticamente, o pós-keynesianismo. São elas: (1) política econômica (cinza); (2) estudos empíricos (preto) e (3) definição do próprio campo (branco). A este último cluster deu-se o nome de "cluster de definição", pois ele contém o termo cuja definição se procura, "Post Keynesian".

Embora a Figura 1 como um todo seja uma definição de "Post Keynesian", segundo a interpretação do finitismo de significado, dado que o objetivo deste trabalho é entender melhor o que é esta corrente em termo de definição, convém concentrar a análise que segue no cluster de definição 
(branco). Por isso, tal cluster foi representado de forma ampliada na Figura 2 e, dentre os vários termos que nele figuram, foram selecionados quatorze (economic policy, Keynes, Kalecki, Paul Davidson, General Theory, Money, effective demand, methodology, history, Cambridge, mainstream, institution, capitalism, macroeconomic) sobre os quais vale a pena tecer alguns comentários. ${ }^{15}$

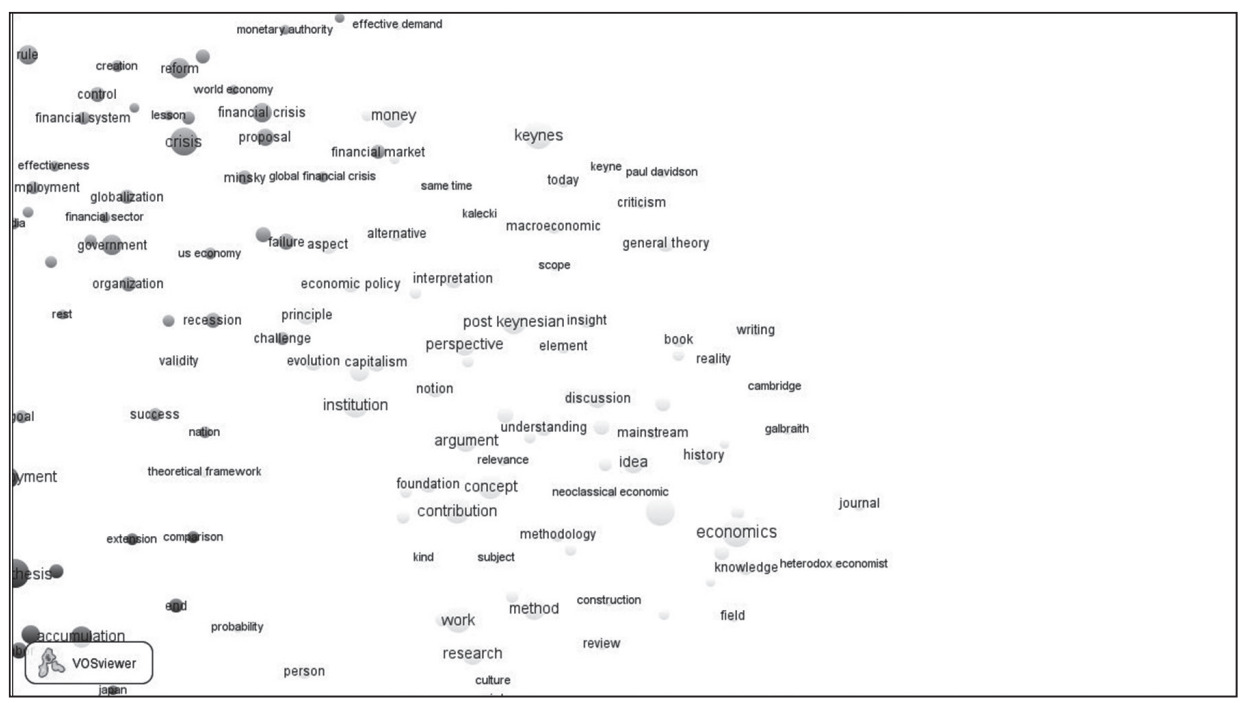

Figura 2 - representação do cluster branco da Figura 1 ampliado

Fonte: JSTOR, figura elaborada pelos autores.

Primeiro, é curioso observar que o termo "política econômica" (economic policy) encontra-se no cluster branco, portanto, no conjunto de definição, e não no cluster cinza, conjunto ao qual foi dado exatamente este nome. Este aparente paradoxo, na verdade, mostra apenas que a corrente póskeynesiana atribui acentuada importância a essa questão - assim como outras correntes que possuem um acentuado enfoque macroeconômico. O termo "política econômica" engloba, de maneira mais geral, os termos "política fiscal" e "política monetária". Como é de conhecimento daqueles que têm contato com a literatura pós-keynesiana, a importância atribuída

${ }^{15}$ Devemos destacar que alguns termos como "perspective", "contribution", "scope", "interpretation", "foundation", "concept", "economics", "method", dentre outros, aparecem no cluster de definição. Eles não foram selecionados como essenciais para delinear a definição propriamente dita, mas são importantes para a conclusão de que o cluster em que se encontram é mesmo o de definição. 
a este item pelos economistas da corrente é grande, o que é evidenciado pela presença do cluster cinza. Isto se deve à maneira como os pós-keynesianos veem a economia. Segundo Arestis $(1996,128)$, é a ideia de que a economia é inerentemente instável que os leva a se preocuparem tanto com questões de política econômica. Aliás, a política econômica é a chave para a mitigação da volatilidade dos ciclos (e do crescimento, também). Tratar da política econômica, em termos da descrição de seus efeitos e de recomendações para a sua condução é parte essencial da definição da corrente pós-keynesiana.

"Keynes" também é um termo de interesse. Embora o seu uso não diferencie os pós-keynesianos dos demais keynesianos, nem denote necessariamente apego às teorias do britânico, uma vez que o pós-keynesianismo nasce eclético, tal como foi visto na subseção 2.1. Não é estranho que Keynes apareça como o economista mais importante no cluster de definição da corrente que leva o seu próprio nome - aliás, diga-se de passagem, entre os quatorze termos selecionados, este é o que tem o maior número de ocorrências.

Entretanto, notável é que o nome de "Kalecki" também aparece, embora com menos ocorrências. O fato de aparecer o nome do economista polonês no cluster de definição evidencia sua importância quando se trata de definir a corrente pós-keynesiana. Desse modo, na presente avaliação linguístico-social, os kaleckianos estariam sim dentro da corrente póskeynesiana. Isso resolveria, pela via do finitismo de significados, um dos debates da corrente sobre suas fronteiras e definições. É interessante notar ainda que o nome de "Paul Davidson" também aparece neste cluster, o que demonstra que, embora nem todos os economistas aceitem sua definição mais restritiva de pós-keynesianismo, sua produção é de fundamental importância no assunto da demarcação das fronteiras.

Outro termo que merece destaque é "General Theory". A presença deste termo somada à ausência de termos com os títulos de outras obras "Treatise on Probability" e "Treatise on Money" - mostra o valor atribuído a este livro pelos economistas e como ele está associado à definição de "Post Keynesian”. É fácil encontrar citações na literatura que corroborem esta ideia. O mapa, portanto, reforça uma convicção: a Teoria Geral é o grande livro do pós-keynesianismo. Embora tenha sido dito acima que a redescoberta do Treatise on Probability foi fundamental para que os pós-keynesianos encontrassem na definição de incerteza de Keynes um argumento 
ontológico em oposição à economia mainstream, é na Teoria Geral que os pós-keynesianos encontram os instrumentos de análise, as recomendações de política, as questões de interesse e, no capítulo final do livro, a filosofia social da corrente.

À esquerda de Keynes o termo dinheiro (Money) também merece destaque quando se fala da definição de pós-keynesianismo. Muitos integrantes desta corrente tomam o aspecto monetário da teoria de Keynes como o mais importante, porém o que realmente singulariza a abordagem póskeynesiana é que a maioria dos seus representantes considera a moeda não neutra tanto no curto como no longo prazo. Essa consideração é um dos pontos que deve ser incluído no rol da definição do pós-keynesianismo, pois se a palavra money é importante, o postulado teórico mais destacado ligado à ela é o da não neutralidade (Arestis 1996, 119).

Além de "dinheiro", outro conceito que singulariza a abordagem pós-keynesiana é a "demanda efetiva" (effective demand). Tal conceito, relacionado ao fato de que habitualmente uma economia não opera em pleno emprego para os pós-keynesianos, esse conceito é um dos poucos utilizados praticamente da mesma forma pelos três grupos de pós-keynesianos apontados por Hamouda e Harcourt (1988).

Outro ponto a ser considerado quando se fala da definição de pós-keynesianismo é a metodologia (methodology). Como lembra Kerr $(2005,480)$, tal questão é um aspecto crucial na definição desta corrente de pensamento. Aliás, a redescoberta do Treatise on Probability como fundamento ontológico da corrente encaixa-se justamente no campo da metodologia da economia. Embora não exista um consenso sobre qual é o método utilizado pelos pós-keynesianos, de acordo com King (2002, 196-7), duas abordagens são comumente ligadas à corrente: a abordagem "babilônica" e o realismo crítico. A primeira perspectiva foi desenvolvida pelo físico Richard Feynman e adaptada para a economia por Sheila Dow. Já o realismo crítico foi transferido para a economia dos escritos do filósofo Roy Bhaskar por Tony Lawson. Talvez ele seria mais restritivo que a abordagem babilônica, e adotá-lo implicaria excluir da corrente artigos publicados pelo JPKE, especialmente os relacionados à pesquisa empírica que utiliza estatística e econometria tradicionais. Mas é preciso marcar que as discussões metodológicas dos economistas simpáticos à corrente não se resumem a essas duas abordagens, adotando, nesse tocante, diversas perspectivas. 
O ponto é que discussões metodológicas e de filosofia da ciência aplicadas à economia são cruciais para os economistas que discutem as fronteiras e a definição de pós-keynesianismo.

Outro termo que aparece nesse setor do mapa e que chama nossa atenção é "história" (history). O uso do termo tem relação íntima com as discussões metodológicas pontuadas acima. Isto porque, segundo Lavoie (2009a, 13-4), a ideia de tempo histórico utilizada pelos pós-keynesianos - em oposição ao tempo lógico, que predomina no mainstream - é um elemento importante para o pós-keynesianismo.

Merecem também comentários dois outros termos que estão próximos de "história", na Figura 2. "Cambridge" provavelmente encontra-se nesta posição por dois motivos. Por um lado, foi o local de onde o conceito de tempo histórico foi integrado à abordagem pós-keynesiana por Robinson e por outro, mais importante, por estar ligado à própria história da corrente, tanto por Keynes mesmo, como por Robinson. Novamente, isso nos leva ao fato de que a construção da história do pensamento da corrente é importante para o entendimento do próprio pós-keynesianismo, bem como para a argumentação em oposição ao mainstream. O segundo termo é "corrente dominante" (mainstream), que se encontra naquela localização do mapa, possivelmente por ser a ideia de tempo histórico muito utilizada para a crítica pós-keynesiana da mesma.

O termo instituição (institution) chama a atenção por estar relativamente próximo de "Post Keynesian" e, embora não seja possível afirmar categoricamente que isto é um indício da existência de uma conexão entre a corrente institucionalista e a pós-keynesiana, é possível dizer que a proximidade entre tais termos denota a importância que as instituições têm dentro da análise pós-keynesiana (Arestis 1996, 113-4). Em seu livro sobre a metodologia da macroeconomia, Sheila Dow $(1996,59-61)$ funde as perspectivas institucionalista e pós-keynesiana para tratar dos princípios e fundamentos metodológicos das várias correntes na macroeconomia. Dentro disso, a autora argumenta que o pós-keynesianismo teria mais aspectos em comum com o institucionalismo do que com, por exemplo, o marxismo ou a economia austríaca (duas outras abordagens heterodoxas). 
Por fim, dois outros termos devem ser mencionados. A presença de Capitalismo (capitalism) no cluster de definição reflete a preocupação dos pós-keynesianos em descrever as características de tal sistema de produção. Já a presença do termo macroeconomia (macroeconomic), somada à ausência de termos que se referem especificamente a questões microeconômicas, constitui forte evidência de que a corrente de pensamento analisada neste artigo dedica-se principalmente a esse tema. Embora Dow e Hillard (2002) mostrem alguns poucos exemplos em outra direção.

Em síntese, no que diz respeito ao uso do termo "Post Keynesian" em economia a Figura 1 mostra que a corrente que o utiliza como nome se caracteriza por dar importância à política econômica, já que aparece um cluster dedicado a ela (cluster cinza), bem como por possuir um considerável número de trabalhos empíricos que utilizam suas ideias, como mostra o cluster preto. Além disso, os termos "política econômica", "Keynes", "Kalecki", "Paul Davidson", "Teoria Geral", "dinheiro", "demanda efetiva”, "metodologia", "história", "Cambridge”, "instituição", "capitalismo" e "macroeconomia" tem um papel importante dentro da análise pós-keynesiana, servindo muitas vezes para diferenciá-la de outras abordagens, como foi visto nos parágrafos acima. Em outras palavras, a Figura 1 é uma representação interessante da acepção do termo "Post Keynesian", segundo a ideia de finitismo de significados, justamente porque apresenta o aglomerado de temas vagamente interligados tratados e utilizados pela corrente pós-keynesiana.

\section{Comentários finais}

O principal objetivo desse artigo foi, tal como exposto na seção 3 , fornecer uma definição não unívoca, não determinista, socialmente determinada e que aproveita as vantagens de certa imprecisão para a corrente de pensamento Pós-keynesiana. Ao considerar o mapa de Co-word, apresentado na subseção 4.2, pode-se dizer que esse objetivo foi atingido. Conseguiu-se aqui encontrar um significado para o termo "Post keynesian", que está de acordo com as concepções wittgensteinianas de como um grupo social atribui significado a uma palavra - finitismo de significados. 
Quanto ao que diz respeito ao poder elucidativo da definição encontrada, cabe lembrar que a interpretação de qualquer definição que esteja de acordo com o finitismo de significados é sempre interativa, ou seja, depende - no caso deste trabalho - do mapa de Co-word em si e de quem o observa. Assim, como cada autor que utiliza o termo "Post keynesian" em seus artigos pode e, muitas vezes, dá um significado particular - "comum" somente a ele - a este termo, assim também cada observador do mapa de Co-word poderá, de acordo com os seus conhecimentos prévios, interpretar a definição gráfica fornecida pelo referido mapa de uma forma diferente. Por isso, os observadores com um conhecimento profundo do pós-keynesianismo e com uma visão mais plural do que é a corrente não fiquem surpreendidos pelos resultados encontrado, o contrário provavelmente acontecerá com quem tem um conhecimento muito compartimentado e restritivo do póskeynesianismo. Em outras palavras, uma definição por finítimos de significados sempre será, em algum grau, subjetiva - que pode ser visto como uma limitação do método.

Contudo, isso não significa que a definição apresentada neste artigo não contenha elementos objetivos, até porque se encontra baseada na coocorrência de palavras, ou seja, em última instância, é sustentada pela evidência de que o termo "Post keynesian" de fato está coocorrendo com o conjunto de palavras que aparece no mapa da subseção 4.2. É isso que permite chegar a algumas afirmações, ainda que não categóricas, sobre o que é o que não é pós-keynesianismo.

A respeito do que é o pós-keynesianismo, pode-se dizer que é uma corrente que dá importância às questões de política econômica, que encontra em Keynes, Kalecki e Davidson elementos que utiliza quando tenta se definir como abordagem teórica e que, para isso se apoia em particular na Teoria Geral e nas reflexões desses e de outros economistas sobre os conceitos de dinheiro e demanda efetiva.

Sobre o que não é o pós-keynesianismo, pode-se dizer - devido às palavras metodologia, história, Cambridge, corrente dominante, instituição, capitalismo, e macroeconomia aparecerem no cluster de definição - que tal corrente não é uma corrente próxima ao mainstream da disciplina.

Por fim, cabe destacar que embora a definição por finitismo de significados apresentada aqui seja relevante por levar em conta grande parte de tudo que a academia já escreveu utilizando o termo "Post keynesian", sua 
contribuição para diferenciar categoricamente a abordagem Pós-keynesiana das demais abordagens heterodoxas ainda é limitada, principalmente pela ausência de trabalhos equivalentes para essas correntes.

\section{Referências}

Abbott, A. 1999. "Department And Discipline. Chicago Sociology At One Hundred.” Chicago: Chicago University Press.

Arestis, P. 1996. "Post-Keynesian Economics: Toward Coherence.” Cambridge Journal Of Economics 20 (1): 111-135.

Arida, P. 1996. “A História Do Pensamento Econômico Como Teoria E Retórica.” In J. M. Rego (Org.). Retórica Na Economia. São Paulo: Editora 34.

Backhouse, R. 2004. “A Suggestion For Clarifying The Study Of Dissent In Economics.” Journal of The History Of Economic Thought 26 (2).

Colander, D., Holt, R. P. F., e Rosser Jr., J. B. 2004. “The Changing Face Of Mainstream Economics.” Review of Political Economy 16 (4).

Dachs, B., Roediger-Schluga, T., Widhalm, C., e Zartl, A. "Mapping Evolutionary Economics: A Bibliometric Analysis.” In European Meeting On Applied Evolutionary Economics. 2001. Viena. Acesso em 17 Jan. 2014. http://widhalm.factlink.net/fsdownload/mappinge. pdf? $\mathrm{v}=1 \& \mathrm{id}=160165 \&$ forumid=256.

Davidson, P. 2003-4. "Setting The Record Straight On A History Of Post Keynesian Economics." Journal Of Post Keynesian Economics 26 (2): 245-271.

Dequech, D. 2007. "Neoclassical, Mainstream, Orthodox, And Heterodox Economics.” Journal of Post Keynesian Economics 30 (2).

Dow, S. C. 1996. “The Methodology Of Macroeconomic Thought: A Conceptual Analysis Of Schools Of Thought In Economics.” Cheltenham: Edward Elgar.

Dow, S. C. 2003. "Babylonian Mode Of Thought.” In J. E. King. The Elgar Companion To Post Keynesian Economics. Cheltenham: Edward Elgar.

Eichner, A. S., e Kregel, J. A. 1975. "An Essay On Post-Keynesian Theory: A New Paradigm In Economics." Journal Of Economic Literature 13 (4): 1293-1314.

Esposito, G. T. 2012. “La Letteratura Post-Keynesiana: 'Scuola Di Pensiero' O 'Tradizione Di Ricerca’? Bergamo: Sestante.

Hamouda, O. F., e Harcourt G. C. 1988. “Post-Keynesianism: From Criticism To Coherence?” Bulletin Of Economic Research 40 (1): 1-30.

Hayes, M. G. 2008. “The Post-Keynesian Economic Study Grup - After 25 Years.” European Journal of Economics And Economic Policies: Intervention 5 (2): 297-300.

Kerr, P. 2005. “A History Of Post-Keynesian Economics.” Cambridge Journal of Economics 29 (3): 475-496.

King, J. E. 2002. “A History Of Post Keynesian Economics Since 1936.” Cheltenham: Edward Elgar.

Klaes, M. 2004. "Evolutionary Economics: In Defence Of 'Vagueness'.” Journal of Economic Methodology $11(3): 359-376$.

Kuhn, T. 2003. “A Estrutura Das Revoluções Científicas.” 8a Edição. São Paulo: Perspectiva.

Lavoie, M. 2005. “Changing Definitions: A Comment On Davidson's Critique Of King's History Of Post Keynesianism.” Journal of Post Keynesian Economics 27 (3): 371-376. 
Lavoie, M. 2009a. "Introduction To Post-Keynesian Economics.” 2 Ed. New York: Palgrave Macmillan.

Lavoie, M. 2009b. "After The Crisis: Perspectives For Post-Keynesian Economics.” In Encontro Internacional Da Associação Keynesiana Brasileira 2: 1-26. Porto Alegre. Acesso em 17 Jan. 2014. http://www.assoeconomiepolitique.org/textes/ml.pdf.

Lee, F. S. 1995. “The Death Of Post Keynesian Economics?” Post Keynesian Study Group Newsletter 1: 1-2.

Lee, F. S. 2009. "A History Of Heterodox Economics: Challenging The Mainstream In The Twentieth Century." New York: Routledge.

Mata, T. 2004. "Constructing Identity: The Post Keynesian And The Capital Controversies." Journal Of The History Of Economic Thought 26 (2): 241-257.

Mongiovi, G. 2003. “Sraffian Economics.” In J. E. King. The Elgar Companion To Post Keynesian Economics. Cheltenham: Edward Elgar.

O’hara, P. A. 2003. “Journal Of Post Keynesian Economics.” In J. E. King. The Elgar Companion To Post Keynesian Economics. Cheltenham: Edward Elgar.

Paula L. F. De, e Ferrari Filho, F. 2010. "The Spread Of Keynesianism In Brazil: The Origins And Experience Of The Brazilian Keynesian Association.” European Journal of Economics And Economic Policies: Intervention 7 (2): 248-255.

Robinson, J. 1972. "The Second Crisis of Economic Theory.” The American Economic Review 62 (1): 1-10.

Van Eck, N. J., e Waltman, L. 2007. "Vos: A New Method For Visualizing Similarities Between Objects.” In H. J. Lenz e R. Decker. Advances In Data Analysis: Proceedings Of The 30th Annual Conference Of The German Classification Society. Berlin: Springer.

Van Eck, N. J., e Waltman, L. 2010. "Software Survey: Vosviewer, A Computer Program For Bibliometric Mapping." Scientometrics 84 (2): 523-538.

Van Eck, N. J., e Waltman, L. 2011. “Text Mining And Visualization Using Vosviewer.” Issi Newsletter 7 (3): 50-54.

Van Eck, N. J., e Waltman, L. 2013. Vosviewer Manual. Rotterdam: Erasmus Universiteit. Acesso em 27 Fev. 2014. http://www.vosviewer.com/documentation/manual_vos viewer_1.5.4.pdf.

Waltman, L., Van Eck, N. J., e Noyons, E. C. M. 2010. “A Unified Approach To Mapping And Clustering Of Bibliometric Networks." Journal Of Informetrics 4 (4): 629-635. 